\title{
THE ROLE OF TASK-ORIENTED VERSUS RELATIONSHIP- ORIENTED LEADERSHIP ON NORMATIVE CONTRACT AND GROUP PERFORMANCE
}

\author{
CARMEN TABERNERO \\ University of Córdoba, Spain \\ M. José Chambel AND LUIS CuRRaL \\ University of Lisbon, Portugal \\ José M. ARANa \\ University of Salamanca, Salamanca, Spain
}

\begin{abstract}
In this paper we examine how groups develop normative contracts based on beliefs about the obligations other members of the group must fulfil in order to achieve group goals. The role played by perceived leadership - task- or relationship-oriented - was analyzed in relation to the development of relational normative contract and group performance. The study sample comprised 72 participants ( 24 groups of 3 members). A member of each team received training to be a group leader (task- or relationship-oriented leader). All groups worked on a simulation program: a complex decision-making managerial task. Group regulatory variables and group processes were evaluated during the simulation. Results showed that task-oriented leaders effected higher group efficacy and positivism among members of the group. In contrast, relationship-oriented leaders effected greater cohesion between the group's members. The final group performance is explained from the perspective of group efficacy and the relational normative contract.
\end{abstract}

Keywords: normative contract, group processes, group performance, group efficacy, taskoriented leadership, relationship-oriented leadership.

Carmen Tabernero, Professor, Department of Social Psychology, University of Córdoba, Córdoba, Spain; María José Chambel and Luis Curral, Department of Organizational Psychology, University of Lisbon, Lisbon, Portugal; and José M. Arana, Associate Professor, University of Salamanca, Salamanca, Spain.

Research for this article was supported by Grants I+D SEJ 2006-07741 and Program José Castillejo 2007 from the Spanish Ministry of Science and Technology.

Appreciation is due to anonymous reviewers.

Please address correspondence and reprint requests to: Professor Carmen Tabernero, Department of Psychology, University of Córdoba, Avenida San Alberto Magno s/n, 14004 Córdoba, Spain. Phone: +34 9572-12605; Fax: 34 9572-12513; Email: carmen.tabernero@uco.es 
Over the last few decades, the issue of psychological contracts has been one of the most salient themes covered in literature on organizational behavior. A psychological contract mediates between the characteristics of an organization and the attitudes and behavior of its members. Theoretical and empirical research into this construct has generally been focused on "individual beliefs, shaped by the organization, regarding terms of an exchange between individuals and their organization" (Rousseau, 1995). It represents employees' perceptions of what compensation, resources, and attitudes can be expected from an exchange partner in return for fulfilling their perceived obligations. Two categories emerge in this exchange: transactional, which defines an exchange of tangible and material resources in which the nature of the exchange is specified and expectations about the duration of the relationship are short term; and relational, which involves unspecified obligations, favors the exchange of socioemotional resources, and presupposes that relationships do not have a specific aim and that they will be maintained in the long term. In these relationships, one party must trust the other to perform future obligations (Millward \& Hopkins, 1998; Rousseau, 1995).

Most researchers focusing on psychological contracts hypothesize that employees develop a psychological contract with an organization depending on the individual's experience in their own work, which in turn is based on their general experience in the organization. However, the psychological contract can be deemed to refer to the individual's perceptions about the conditions of exchange agreed between the individual and the other party (Rousseau, 1989), bearing in mind that it is not necessary for one of the parties to be the organization itself. In fact, "individuals may establish psychological contracts outlining the expected reciprocation with immediate superiors, teammates, and the organization..." (Shore et al., 2004, p. 300). More specifically, Marks (2001) claims that the concept of a psychological contract needs to be redefined, taking into consideration that it can establish differences between the different entities which operate at different organizational levels. Therefore, the number and type of psychological contracts which can be established by individuals in their working environment depend on the type of organization and the working process being developed. However, as stated by Ilgen, Hollenbeck, Johnson, and Jundt (2005), organizations are increasingly structured in teams or working groups and, therefore, the psychological contracts established in relation to working groups need to be investigated. This type of contract can be defined as the perception of each group member regarding the supposed obligations of each of the parties, both their own and those of their colleagues (Lee, Tinsley, \& Chen, 2000).

Furthermore, empirical evidence indicates that social interaction in working groups or teams produces shared phenomena (Hinsz, Tindale, \& Vollrath, 1997; Walter \& Bruch, 2008). Nicholson and Johns (1985) argue for the existence of a shared psychological contract when members of a team experience a common set 
of psychological contracts. Rousseau (1995) refers to the existence of normative contracts, in other words, psychological contracts shared by the members of a team. A working team can share beliefs about the type of relationships established between the members, who maintain a set of beliefs which constitute the reality of that group. Beliefs about reciprocity and exchange undergo changes, especially in the initial stages of group interaction, as a reflex of the process of adaptation to reality (De Vos, Buyens, \& Schalk, 2003). Thus, when members of a group interact in order to resolve a common task, they are expected to end up sharing the same kind of psychological contract (Shore et al., 2004). Hence, groups who work on a task over time should develop a psychological contract in relation to the group, which is shared by that group. In addition, as the group's members spend more time in the accomplishment of a common task, it is more likely that they will develop a relational rather than a transactional contract (Rousseau, 1995).

Therefore, in this study we aimed to analyze the influence of the perception of task behavior and relationship behavior of the group leader on the development of relational versus transactional normative contracts, group processes, and team performance. The psychological contract generation model presented by Rousseau (1995) emphasizes the importance of messages and communications sent out by the organization, which are normally disseminated among employees through the supervision of psychological contract creation managers. Through such messages and norms of conduct, these actors make the aspects considered by the members of the team more explicit obligations.

Although relatively little research has been conducted regarding the direct influence of higher-level processes on the creation of the psychological contract, there is some evidence that employees who share the same manager develop a greater level of agreement regarding the terms which make up the psychological contract (Shore et al., 2004). Leaders' behavior may not be fully accountable for a team's success or failure (Meindl, Ehrlich, \& Dukerich, 1985), but there are circumstances under which it can make a difference (Hackman \& Wageman, 2005a). Assuming that team performance depends upon a combination of factors, including the amount of effort team members put into task accomplishment, the right choice of performance strategies, and the diversity of knowledge and skills members bring to the team, a leader can facilitate team effectiveness by selecting members with the required diversity of knowledge and skills, helping members to enhance their level of effort, and choosing the appropriate task strategies (Hackman \& Wageman, 2005b). In some circumstances, the leader does not have the opportunity to select the best combination of people to perform a specific task. In this case, the behavior of team leaders should focus more on the promotion of positive group process gains (Steiner, 1972). In short, successfully leading a team involves establishing clear and challenging goals, 
and helping to specify basic norms for cooperation in order to accomplish these goals.

Two distinct behavioral roles of leaders were defined by the Ohio State group (Stogdill, 1950) as a framework to categorize the array of leadership styles that team leaders could adopt. Initiating structure - task-oriented leadership - expresses the degree to which a leader defines the roles of their followers, focuses on goal achievement, and establishes well-defined patterns of communication. Consideration - relationship-oriented leadership - expresses the degree to which a leader shows concern and respect for their followers, looks out for their welfare, and expresses appreciation and support (Bass, 1990a, 1990b). A meta-analytical study of the relationship between these two leadership behavioral roles and different outcomes revealed that both roles have a major effect in this regard. Consideration had a stronger effect on follower satisfaction (job and leader satisfaction, and motivation) whereas initiating structure had a slightly stronger effect on leader performance. Consideration was also more closely related to leader effectiveness, although both roles had a moderate to strong effect on effectiveness (Judge, Piccolo, \& Ilies, 2004). These results support the idea that consideration for followers and structuring of group activities towards goal accomplishment are essential components of effective leadership.

In a study with a design similar to our own, Durham, Knight, and Locke (1997) manipulated the roles team leaders could assume by performing a simulation task. In teams with a coordinator, all members shared equal responsibility for determining the team's strategy and directing its activities. The leader's role was to encourage active participation and sharing of ideas by all members. In teams with a commander, the leader was assigned to determine the strategy and direct the team's activities. The results revealed that coordinator leaders had a positive effect on team tactics, which in turn had positive effects on team performance. Commander leaders, on the other hand, had no effect on team performance. These results suggest that leadership roles make a difference when teams have to learn a new task requiring coordination. Zaccaro, Rittman, and Marks (2001) state that there are numerous studies about leadership and group work which examine the influence of the leader on group effectiveness, but very little is known about how leaders create effective groups. Some authors (Chen \& Bliese, 2002; Gibson, 2003; Gully, Incalcaterra, Joshi, \& Beaubien, 2002) maintain that new sources should be sought. For this reason, in this study we suggest that the development of normative contracts acts as a precursor to perceived group efficacy and one of the key factors in this relationship could be the type of leadership perceived.

Further support for the importance of leaders' behavior in team success was provided by research examining the relationship between leadership, group regulatory processes, and group performance over time (Sivasubramaniam, Murry, Avolio, \& Jung, 2002). One of the most sought-after regulatory processes 
after cohesion and the establishment of group goals is perceived group efficacy (Gibson, 2003; Lee \& Farh, 2004; Pescosolido, 2003). Group or collective efficacy is defined as a group's shared beliefs in its combined capability to organize and implement the courses of action required to attain a given level of achievement in new and challenging tasks (Bandura, 2000). Marks, Sabella, Burke, and Zaccaro (2002) claim that group efficacy influences coordination processes and team performance in both routine and new environments. Numerous researchers highlight the power of group efficacy in explaining group behavior and performance in different contexts (Bandura, 1997; Gibson, 2001). Further support for the relationship between group efficacy and group performance can be found in the many studies reviewed by Gully et al. (2002). In summary, groups who work on a task together over a period of time develop a strong sense of group efficacy, group satisfaction, and group goals, all of which are linked to group performance. The results analyzed previously suggested that leader behavior had a positive effect on team performance through the mediating role of the relational normative contract and group regulatory processes, and these were the core points used to develop the following hypotheses:

Hypothesis 1: Relationship-oriented leadership will develop a stronger relational normative contract between group members than will task-oriented leadership.

Hypothesis 2: Task-oriented leadership will develop a stronger group efficacy and positive affect between group members.

Hypothesis 3: Relationship-oriented leadership will develop stronger cohesion between group members.

Hypothesis 4: Task-oriented leadership will obtain a better performance in managerial and complex tasks than within groups with a relationship-oriented leadership.

\section{METHOD}

\section{Participants}

The participants in this study were 72 university students in the final year of their Psychology degrees, with an average age of $24.26(S D=4.06)$. The students were divided into 24 groups of three members. The participants were all studying Social Psychology at a Spanish university. The percentages of men and women were $22.7 \%$ and $77.3 \%$ respectively. No differences were found between the variables in accordance with age or gender. The study was conducted as part of the course, and the task was presented to students as a decision-making exercise.

\section{Task And Procedure}

One person from each group was chosen at random to follow a leadership 
training course, created following the indications of Yukl (1999). These individuals had to perform tasks which would develop their leadership behavior oriented towards the tasks and relationships within the group. Twelve leaders received strong training in task-oriented leadership (the leader clarifies the aims, organizes the steps of the task, manages and coordinates the specific task for each group member, and informs about evaluation criteria) and the other 12 leaders received strong training in relationship-oriented leadership (leader asks and makes suggestions to each group member, shows confidence in the team's ability to achieve the task, and gives support to each group member to successfully complete the task). Each leader also received a book of instructions explaining the conduct which they should follow. In the first practical group session, all the participants, having completed the task, answered the relational normative contract questionnaire. Subsequently, the groups carried out a task for 12 weeks of simulated program (Wood \& Bailey, 1985) and answered a self-assessment questionnaire about the group's processes (perceived group efficacy, group goals, group affective state) as well as other questionnaires which evaluated group cohesion, task focus, and perception of the leader's behavior.

\section{Measures}

Normative contract was evaluated using an adaptation of a questionnaire drawn up by Millward and Hopkins (1998) comprising 18 items, based on a 5-point scale, where $1=$ totally disagree, and $5=$ totally agree. In the adaptation of the questionnaire we changed the original referent of "organization" to "group". Ten items were grouped to explain the transactional contract created within the working groups $\left(\alpha_{1}=.90, \alpha_{2}=.80\right)$, for example, "I expect my effort to be rewarded by this team", and the other eight items explained the relational contract $\left(\alpha_{1}=.74, \alpha_{2}=.91\right)$, for example, "Working with this team is more important for me than the mere completion of the task". The questionnaire was applied at two distinct times. First, at the beginning of the simulation game, which occurred six weeks after the group members started to work together and, second, at the end of the simulation.

Perceived group efficacy was recorded using a multi-item efficacy scale which described nine levels of production performance, ranking from $30 \%$ better to $40 \%$ worse than the standard production time. Team members rated the strength of the perceived group efficacy which they could get the group to perform at each of the levels of productivity conveyed. The ratings were made using a 10-point scale ranging from $1=$ no confidence at all to $10=$ total confidence. The strength of the perceived group efficacy was the sum of the confidence scores for the nine levels of organizational performance. The internal reliability coefficients for the collective efficacy scores were high for both assessments $\left(\alpha_{1}=.94, \alpha_{2}=.94\right)$, and consistent with those found in other studies using equivalent self-efficacy measures (e.g., Tabernero \& Wood, 1999; Wood \& Bandura, 1989). 
The shortened version of the Positive Affect and Negative Affect Scales (PANAS; Watson, Clark, \& Tellegen, 1988) was applied, comprising 10 items evaluated using a 5-point scale, where $1=$ not at all and $5=$ completely. Five items were used to evaluate the group's positive affective state $(\alpha=.83)$ and five for the negative affective state $(\alpha=.84)$.

Group processes Following completion of the group decision-making task, individual participants completed a reduced version of the Group Style Questionnaire developed and validated by Barry and Stewart (1997). Participants were asked to "Evaluate how your group functioned while working on the Furniture Factory" and to "Circle the number that best represents your beliefs about your group and its activities while working on the Furniture Factory task". All items had a 5-point scale with anchor statements, ranging from $1=$ very little to $5=$ very much. The 12-item Group Style Questionnaire included three items to measure task focus, e.g., "In group discussions we frequently drifted off the point" (reverse scored), and nine items to measure group cohesion, for example, "There is a feeling of unity and cohesion within this group". The internal reliability coefficients for both task focus $(\alpha=.76)$ and group cohesion $(\alpha=.93)$ were high and consistent with past research using these scales (Barry \& Stewart, 1997).

Perception of leadership The two dimensions defined by Yukl (1999) were adapted, using six items $(\alpha=.92)$ which evaluated task-oriented leader behavior for example, "S/he clearly explains the responsibilities involved in each of the tasks" and four items $(\alpha=.93)$ which evaluated relationship-oriented leader behavior for example, "S/he shows confidence in the team's capacity to resolve the task". The participants answered the ten items using a 5-point scale, where 1 $=$ totally disagree and $5=$ totally agree .

\section{RESULTS}

\section{IMPACT OF PERCEIVEd TASK-ORIENTEd LEADERSHIP ON TyPES OF RELATIONAL Normative Contract, Group Processes, and Performance}

In order to test the manipulation of the training on task-oriented leadership, perceived task-oriented leadership was evaluated. Perceived leadership was dichotomized in accordance with the distribution of answers on a normal curve $(M=3.92 ; S D=0.61)$ thereby creating a dummy variable where $0=$ low taskoriented leadership and $1=$ high task-oriented leadership across the median score. A total agreement was found between groups with perceived task-oriented leadership and groups who worked with a leader who had been given taskoriented training. To understand the impact of this style of perceived leadership on the evolution of the relational normative contract, a $t$ test was performed to compare differences between the means, revealing no differences at the first 
point but a significant difference at the second point, where those who perceived a more task-oriented style of leadership developed a more intense relational normative contract than those who perceived less task-oriented leadership style (see Table 1).

Regarding the emergent states which develop through group interaction, group cohesion, and task focus, no significant differences were detected in accordance with the intensity of perceived task-oriented leadership. In relation to group processes, significant differences were found in terms of the groups that perceived a more intense task-oriented style of leadership and with the expected correlation to perceived group efficacy judgments, positive group affective state, and negative group affective state. Finally, when analyzing the effect of perceived task-oriented leadership on performance, significant differences were found in the second and third trial blocks, whereas the differences in the first block were not significant although they correlated as expected.

TABLE 1

Differences Regarding Relational Normative Contract, Group Processes, and Performance Between High Task-oriented Leadership (TOL) and Low Task-oriented LEADERSHIP

\begin{tabular}{|c|c|c|c|}
\hline & High TOL & Low TOL & High TOL \\
\hline & \multicolumn{2}{|c|}{ Time 1} & Time 2 \\
\hline Normative contract & \multicolumn{2}{|c|}{$t=-1.71 ; d f=22 ; p<.10 ; \eta^{2}=.11$} & $t=-2.23 ; d f=22 ; p<.05 ; \eta^{2}=.18$ \\
\hline$M(S D)$ & $2.51(0.60)$ & $2.38(0.64)$ & $2.59(0.71)$ \\
\hline Cohesion & \multicolumn{2}{|c|}{$t=-.33 ; d f=22 ; p<.05 ; \eta^{2}=.01$} & $t=-1.51 ; d f=22 ; p<.05 ; \eta^{2}=.06$ \\
\hline$M(S D)$ & $3.95(0.58)$ & $3.88(0.51)$ & $4.06(0.62) \quad 3.78(0.61)$ \\
\hline Task focus & \multicolumn{2}{|c|}{$t=-1.51 ; d f=22 ; p<.05 ; \eta^{2}=.09$} & $t=-1.29 ; d f=22 ; p<.05 ; \eta^{2}=.07$ \\
\hline$M(S D)$ & $4.19(0.61)$ & $3.84(0.52)$ & $3.84(0.57)$ \\
\hline \multirow{2}{*}{\multicolumn{3}{|c|}{$\begin{array}{l}\text { Group efficacy } \\
M(S D)\end{array}$}} & \multirow{2}{*}{$t=-2.74 ; d f=22 ; p<.01 ; \eta^{2}=.26$} \\
\hline & & & \\
\hline \multirow{2}{*}{\multicolumn{3}{|c|}{$\begin{array}{l}\text { Positive group affective state } \\
M(S D)\end{array}$}} & \multirow{2}{*}{$\begin{array}{cc}t=-2.53 ; d f=22 ; p<.05 ; \eta^{2}=.23 \\
3.46(0.62) & 2.91(0.60)\end{array}$} \\
\hline & & & \\
\hline \multirow{2}{*}{\multicolumn{3}{|c|}{$\begin{array}{l}\text { Negative group affective state } \\
M(S D)\end{array}$}} & \multirow{2}{*}{$\begin{array}{cc}t=3.14 ; d f=22 ; p<.01 ; \eta^{2}=.31 \\
2.07(0.66) & 1.32(0.50)\end{array}$} \\
\hline & & & \\
\hline \multirow{4}{*}{$\begin{array}{l}\text { Group } \\
\text { performance } \\
M(S D)\end{array}$} & \multicolumn{2}{|c|}{$\begin{array}{c}\text { First block } \\
t=-1.73 ; d f=22 ; p<.05 ; \eta^{2}=.12\end{array}$} & $\begin{array}{c}\text { Second block } \\
t=-2.70 ; d f=22 ; p<.05 ; \eta^{2}=.25\end{array}$ \\
\hline & $101.57(8.21)$ & $101.57(8.21)$ & $110.86(3.51)$ \\
\hline & & & \multirow{2}{*}{$\begin{array}{c}\text { Third block } \\
t=-2.35 ; d f=22 ; p<.05 ; \eta^{2}=.27 \\
123.18(3.08)\end{array}$} \\
\hline & & & \\
\hline
\end{tabular}


IMPACT OF PERCEIVEd RELATIONSHIP-ORIENTEd LEADERSHIP ON TyPES OF Relational Normative Contract, Group Processes, and Performance

As in the previous section, in order to to test the manipulation of training on relationship-oriented leadership, perceived relationship-oriented leadership was evaluated. Perceived leadership was dichotomized in accordance with the distribution of answers on a normal curve $(M=4.12 ; S D=0.47)$ thereby creating a dummy variable where $0=$ low relationship-oriented leadership and $1=$ high relationship-oriented leadership across the median score. A total agreement was found between groups with perceived relationship-oriented leadership and groups who worked with a leader who had been given relationship-oriented training. To ascertain the impact of this style of perceived leadership on the evolution of the relational normative contract, a $t$ test was performed, which revealed no differences at the first point but did reveal differences at the second point, where those who perceived a more relationship-oriented leadership style developed a more intense relational normative contract than those who perceived a less relationship-oriented leadership style (see Table 2).

TABLE 2

Differences Regarding Relational Normative Contract, Group Processes, and Performance Between High Relationship-oriented Leadership (TOL) and Low RELATIONSHIP-ORIENTED LEADERSHIP

\begin{tabular}{lcccc}
\hline & High ROL & Low ROL & High ROL & Low ROL \\
& \multicolumn{2}{c}{ Time 1} & \multicolumn{2}{c}{ Time 2} \\
\hline Normative contract & $t=-1.15 ; d f=22 ; p<.05 ; \eta^{2}=.05$ & $t=-1.96 ; d f=22 ; p<.05 ; \eta^{2}=.15$ \\
$M(S D)$ & $2.66(0.58)$ & $2.55(0.60)$ & $3.18(0.59)$ & $2.59(0.71)$ \\
\hline Cohesion & $t=-2.86 ; d f=22 ; p<.01 ; \eta^{2}=.27$ & $t=-2.47 ; d f=22 ; p<.05 ; \eta^{2}=.22$ \\
$M(S D)$ & $4.31(0.54)$ & $3.70(0.48)$ & $4.27(0.55)$ & $3.73(0.52)$ \\
\hline Task focus & $t=-1.11 ; d f=22 ; p<.05 ; \eta^{2}=.05$ & $t=-1.60 ; d f=22 ; p<.05 ; \eta^{2}=.10$ \\
$M(S D)$ & $n s$ & $n s$ & $n s$ & $n s$ \\
& $4.03(0.61)$ & $3.79(0.44)$ & $4.11(0.66)$ & $3.72(0.54)$ \\
\hline Group efficacy & & $t=-0.54 ; d f=22 ; p>.05 ; \eta^{2}=.01$ \\
$M(S D)$ & $n s$ & $n s$ \\
& & $6.21(1.53)$ & $5.90(1.40)$ \\
\hline Positive group affective state & & $t=-0.30 ; d f=22 ; p<.05 ; \eta^{2}=.01$ \\
$M(S D)$ & $n s$ & $n s$ \\
& & $3.22(0.64)$ & $3.15(0.57)$ \\
\hline Negative group affective state & & $t=-0.46 ; d f=22 ; p>.05 ; \eta^{2}=.01$ \\
$M(S D)$ & $n s$ & $n s$ \\
& & $1.76(0.81)$ & $1.63(0.58)$ \\
\hline
\end{tabular}


Table 2 continued

\begin{tabular}{|c|c|c|c|c|}
\hline & High ROL & Low ROL & High ROL & Low ROL \\
\hline & \multicolumn{2}{|c|}{ Time 1} & \multicolumn{2}{|c|}{ Time 2} \\
\hline \multirow{3}{*}{$\begin{array}{l}\text { Group } \\
\text { performance } \\
M(S D)\end{array}$} & \multicolumn{2}{|c|}{$\begin{array}{c}\text { First block } \\
t=-.01 ; d f=22 ; p<.05 ; \eta^{2}=.01\end{array}$} & \multicolumn{2}{|c|}{$\begin{array}{c}\text { Second block } \\
t=-1.87 ; d f=22 ; p<.07 ; \eta^{2}=.14\end{array}$} \\
\hline & $\begin{array}{c}n s \\
97.10(5.98)\end{array}$ & $\begin{array}{c}n s \\
97.07(10.57)\end{array}$ & $\begin{array}{c}n s \\
109.66(7.50)\end{array}$ & $\begin{array}{c}n s \\
102.75(10.33)\end{array}$ \\
\hline & & & $t=-1.43 ; d f=$ & 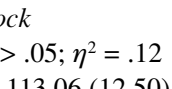 \\
\hline
\end{tabular}

In terms of group processes, the differences in relation to the groups that perceived a more relationship-oriented style of leadership were not significant in terms of perceived group efficacy judgments, positive group affective state, and negative group affective state. As for the emergent states developed through group interaction, significant differences were found in relation to perceived group cohesion at both points of task development. Groups with a significantly more relationship-oriented perceived style of leadership also perceived greater group cohesion at the first point and the second point. However, no significant differences were found in terms of the intensity of perceived relationshiporiented leadership and the degree to which the group was focused on the task. Finally, when analyzing the effect of perceived relationship-oriented leadership on performance, no significant differences were found in any of the blocks analyzed.

\section{Performance, Relational Normative Contract, and Group Processes}

A regression analysis was performed to ascertain which variables predict group performance. A model was developed with the relational contract and group efficacy as predictors of group performance. This model explained $57 \%$ of the total variance $\left(R_{\text {Adj }}^{2}=.57 ; F_{(2,20)}=16.01, p<.01\right)$, according to which the relational contract $(\beta=.42 ; p<.01)$ and perceived group efficacy judgment $(\beta=$ $.70 ; p<.001)$ predict the final performance attained by the group.

\section{DISCUSSION}

The results show how the perception of the leader's behavior influences the development of relational normative contracts, group processes, and performance. Specifically, task-oriented and relationship-oriented leadership behavior roles have a positive effect on the development of transactional and relational normative contracts, respectively. With reference to the emergent states which develop through group interaction, the results revealed that relationship-oriented 
leaders generated greater cohesion between members of the group, whereas a more task-oriented style of leadership did not create differences in the emergent states. The effect of leadership style on group processes was different: taskoriented leaders induced greater group efficacy, a more positive and less negative affective state among members of the group, whereas more relationship-oriented leaders did not bring significant differences in relation to group processes. These results are consistent in terms of the effect of leadership style on performance. Groups who perceived their leaders as more task-oriented achieved higher levels of task accomplishment. No differences were found in performance when leaders evidenced a more relationship-oriented style of leadership.

The results of this study generally provide support to the findings of other studies, which have shown the significant role played by the leader in the development of group processes. Schaubroeck, Lam, and Cha (2007) argue that a leadership style which focuses on task achievement is linked with better performance and that this relationship is mediated by perceived efficacy among the members of the group. In other words, as revealed by our results, the style of leadership influences group efficacy and consequently group performance. The study carried out by Bono, Foldes, Vinson, and Muros (2007) also maintains the importance of leadership style. These authors claim that individuals who perceive a more task-oriented style of leadership experience more positive emotions, including interaction with their colleagues.

The Ohio studies, such as Stogdill (1950), Fleishman (1957), Hemphill and Coons (1957), and Halpin and Winer (1957), are still a reference for practical leadership studies. In this sense, Blake and Mouton (1982) distinguish between leadership behavior focusing on task achievement (e.g., organization of work, definition of responsibilities, and distribution of tasks) and the establishment of relationships with other members of the group (respect, loyalty, affective commitment), highlighting that future researchers should continue to explore the effect of different leadership styles on group processes. In this respect, different leadership focuses can influence the development of normative contracts, group processes, and performance. According to the model presented in this study, it could be maintained that leaders who focus on relationships set more long-term objectives and for this reason alone they have an effect on emergent states, whereas task-oriented leaders will have an effect on task performance in the shorter term. Hence, it would be very useful to conduct longitudinal research which would enable the effects of different leadership styles to be analyzed over time, as well as their effect in relation to different types of tasks which have higher or lower degrees of structure.

One well-established hypothesis from path-goal theory (House, 1996) is that the leader's directives or instrumental behavior will be effective in situations with a low degree of group task structure because, in these situations, such behavior 
helps group members to structure their unclear tasks, and therefore helps them to achieve group goals. This hypothesis has received wide support from metaanalytical testing (Indvick, 1986). As in the study by Yukl (1999), our results indicate that the initial formulation of the two leadership focuses should be differentiated in studies which aim to validate team leadership processes.

As expected, leaders who focus on the definition of tasks, the definition of responsibilities, and the organization of work among members of the team, whilst maintaining open communication and fostering cohesion and commitment among members of the team, help to create and develop more relational and less transactional normative contracts among the members of the team they lead (Rousseau, 1995; Shore et al., 2004).

Although one of the possible limitations of this study is the fact that it was carried out in a laboratory context, which does not allow for generalization in the real working context owing to the lack of ecological validity, most studies carried out in relation to psychological contracts have been conducted using correlational methodologies, applying questionnaires, and self-reporting, which has attracted some critical comments. Hence, the methodology used to date has not enabled researchers to understand the dynamic creation process of the psychological contract, although past research has helped to provide a theoretical assumption (Conway \& Briner, 2005). Also, it would be interesting to study the effect of task- versus relationship-oriented leadership on other complex tasks with a stronger relationship request, communication processes, and agreement between group members. A strong effect of relationship-oriented leadership and the relational contract would be expected. Therefore, further research is required using longitudinal designs within the organizational context.

\section{REFERENCES}

Bandura, A. (1997). Self-efficacy: The exercise of control. New York: W. H. Freeman.

Bandura, A. (2000). Exercise of human agency through collective efficacy. Current Directions in Psychological Science, 9(3), 75-78.

Barry, B., \& Stewart, G. L. (1997). Composition, process, and performance in self-managed groups: The role of personality. Journal of Applied Psychology, 82(1), 62-78.

Bass, B. M. (1990a). Bass \& Stogdill's handbook of leadership: Theory, research, and managerial applications (3rd ed.). New York: Free Press.

Bass, B. M. (1990b). From transactional to transformational leadership: Learning to share the vision. Organizational Dynamics, 18(3), 19-31.

Blake, R. R., \& Mouton, J. S. (1982). Grid principles versus situacionalism: A final note. Group and Organization Studies, 7(2) 211-215.

Bono, J. E., Foldes, H. J., Vinson, G., \& Muros, J. P. (2007). Workplace emotions: The role of supervision and leadership. Journal of Applied Psychology, 92(5), 1357-1367.

Chen, G., \& Bliese, P. D. (2002). The role of different levels of leadership in predicting self- and collective efficacy: Evidence for discontinuity. Journal of Applied Psychology, 87(3), 549-556. 
Conway, N., \& Briner, R. B. (2005). Understanding psychological contracts at work: A critical evaluation of theory and research. Oxford, UK: Oxford University Press.

De Vos, A., Buyens, D., \& Schalk, R. (2003). Psychological contract development during organizational socialization: Adaptation to reality and the role of reciprocity. Journal of Organizational Behavior, 24(5), 537-559.

Durham, C. C., Knight, D., \& Locke, E. A. (1997). Effects of leader role, team-set goal difficulty, efficacy, and tactics on team effectiveness. Organizational Behavior and Human Decision Processes, 72(2), 203-231.

Fleishman, E. A. (1957). A leader behavior description for industry. In R. M. Stogdill \& A. E. Coons (Eds.), Leader behavior: Its description and measurement (pp. 103-119). Columbus, OH: Ohio State University, Bureau of Business Research.

Gibson, C. B. (2001). From knowledge accumulation to accommodation: Cycles of collective cognition in work groups. Journal of Organizational Behavior, 22(2), 121-134.

Gibson, C. B. (2003). Factors related to the formation of group efficacy. Journal of Applied Social Psychology, 33(10), 2153-2186.

Gully, S. M., Incalcaterra, K. A., Joshi, A., \& Beaubien, J. M. (2002). A meta-analysis of teamefficacy, potency, and performance: Interdependence and level of analysis as moderators of observed relationships. Journal of Applied Psychology, 87(5), 819-832.

Hackman, J. R., \& Wageman, R. (2005a). When and how team leaders matter. In B. M. Staw, R. M. Kramer, \& M. Roderick (Eds.), Research in organizational behavior: An annual series of analytical essays and critical reviews (Vol. 26; pp. 37-74). Greenwich, CT: JAI Press.

Hackman, J. R., \& Wageman, R. (2005b). A theory of team coaching. Academy of Management Review, 30(2), 269-287.

Halpin, A. W., \& Winer, B. J. (1957). A factorial study of the leader behavior descriptions. In R. M. Stogdill \& A. E. Coons (Eds.), Leader behavior: Its description and measurement (pp. 39-51). Columbus, OH: Ohio State University, Bureau of Business Research.

Hemphill, J. K., \& Coons, A. E. (1957). Development of the leader behavior description questionnaire. In R. M. Stodgill \& A. E. Coons (Eds.), Leader behavior: Its description and measurement (pp. 6-38). Columbus, OH: Ohio State University, Bureau of Business Research.

Hinsz, V. B., Tindale, R. S., \& Vollrath, D. A. (1997). The emerging conceptualization of groups as information processors. Psychological Bulletin, 121(1), 43-64.

House, R. J. (1996). Path-goal theory of leadership: Lessons, legacy, and a reformulated theory. Leadership Quarterly, 7(3), 323-352.

Ilgen, D. R., Hollenbeck, J. R., Johnson, M., \& Jundt, D. (2005). Teams in organizations: From InputProcess-Output models to IMOI models. Annual Review of Psychology, 56, 517-543.

Indvick, J. (1986). Path-goal theory of leadership: A meta-analysis. Proceedings of the Academy of Management Meetings, 46, 189-192.

Judge, T. A., Piccolo, R. F., \& Ilies, R. (2004). The forgotten ones? The validity of consideration and initiating structure in leadership research. Journal of Applied Psychology, 89(1), 36-51.

Lee, C., \& Farh, J. L. (2004). Joint effects of group efficacy and gender diversity on group cohesion and performance. Applied Psychology: An International Review, 53(1), 136-154.

Lee, C., Tinsley, C. H., \& Chen, G. Z. X. (2000). Psychological and normative contracts of work group members in the United States and Hong Kong. In D. M. Rousseau \& R. Schalk (Eds.), Psychological contracts in employment: Cross-national perspectives (pp. 87-103). Thousand Oaks, CA: Sage.

Marion, R., \& Uhl-Bien, M. (2001). Leadership in complex organizations. Leadership Quarterly. 12, 389-418.

Marks, A. (2001). Developing a multiple foci conceptualization of the psychological contract. Employee Relations, 23(5), 454-469. 
Marks, M. A., Sabella, M. J., Burke, C. S., \& Zaccaro, S. J. (2002). The impact of cross-training on team effectiveness. Journal of Applied Psychology, 87, 3-13.

Meindl, J. R., Ehrlich, S. B., \& Dukerich, J. M. (1985). The romance of leadership. Administrative Science Quarterly, 30(1), 78-102.

Millward, L. J., \& Hopkins, L. J. (1998). Psychological contracts, organizational and job commitment. Journal of Applied Social Psychology, 28(16), 1530-1536.

Nicholson, N., \& Johns, G. (1985). The absence culture and the psychological contract: Who's in control of absence? Academy of Management Review, 10(3), 397-407.

Pescosolido, A. T. (2003). Group efficacy and group effectiveness: The effects of group efficacy over time on group performance and development. Small Group Research, 34, 20-42.

Rousseau, D. M. (1989). Psychological and implied contracts in organizations. Employee Responsibilities and Rights Journal, 2(2), 121-139.

Rousseau, D. M. (1995). Psychological contracts in organizations: Understanding written and unwritten aggrements. London: Sage.

Schaubroeck, J., Lam, S. S. K., \& Cha, S. E. (2007). Embracing transformational leadership: Team values and the impact of leader behavior on team performance. Journal of Applied Psychology, 92(4), 1020-1030.

Shore, L. M., Tetrick, L. E., Taylor, M. S., Coyle-Shapiro, J. A.-M., Liden, R. C., McLean Parks, J., et al. (2004). The employee-organization relationship: A timely concept in a period of transition. Research in Personnel and Human Resources Management, 23, 291-370.

Sivasubramaniam, N., Murry, W. D., Avolio, B. J., \& Jung, D. I. (2002). A longitudinal model of the effects of team leadership and group potency on group performance. Group and Organization Management, 27(1), 66-96.

Steiner, I. D. (1972). Group process and productivity. New York: Academic Press.

Stogdill, R. M. (1950). Leadership, membership and organization. Psychological Bulletin, 47, 1-14.

Tabernero, C., \& Wood, R. E. (1999). Implicit theories versus the social construal of ability in selfregulation and performance on a complex task. Organizational Behavior and Human Decision Processes, 78(2), 104-127.

Walter, F., \& Bruch, H. (2008). The positive group affect spiral: A dynamic model of the emergence of positive affective similarity in work groups. Journal of Organizational Behavior, 29(2), 239261.

Watson, D., Clark, L. A., \& Tellegen, A (1988). Development and validation of brief measures of positive and negative affect: The PANAS scales. Journal of Personality and Social Psychology, 54(6) 1063-1070.

Wood, R. E., \& Bailey, T. C. (1985). Some unanswered questions about goal effects: A recommended change in research methods. Australian Journal of Management, 10, 61-73.

Wood, R. E., \& Bandura, A. (1989). Impact of conceptions of ability on self-regulatory mechanisms and complex decision making. Journal of Personality and Social Psychology, 56(3), 407-415.

Yukl, G. (1999). An evaluation of conceptual weaknesses in transformational and charismatic leadership theories. The Leadership Quarterly, 10(2), 285-305.

Zaccaro, S. J., Rittman, A. L., \& Marks, M. A. (2001). Team leadership. Leadership Quarterly, 12, 451-483. 